\title{
Role and Mechanism of Galactose-Alpha-1,3-Galactose in the Elicitation of Delayed Anaphylactic Reactions to Red Meat
}

\author{
Christiane Hilger $^{1}$ (D) Jörg Fischer ${ }^{2} \cdot$ Florian Wölbing $^{3} \cdot$ Tilo Biedermann $^{3,4}$
}

Published online: 23 January 2019

(C) The Author(s) 2019

\begin{abstract}
Purpose of Review The alpha-Gal ( $\alpha$-Gal) syndrome is characterized by the presence of IgE antibodies directed at the carbohydrate galactose-alpha-1,3-galactose ( $\alpha$-Gal). In this article, we review the presence of $\alpha$-Gal in food and non-food sources; we discuss the evolutionary context of the antibody response to $\alpha$-Gal and highlight immune responses to $\alpha$-Gal and other carbohydrates.

Recent findings IgE antibodies have been associated with delayed allergy to red meat. In addition to food, drugs, and other products of animal origin are increasingly perceived as a risk for patients sensitized to $\alpha$-Gal. The link between tick bites and anti- $\alpha$-Gal IgE-antibody production that has been established first by epidemiological studies has now been confirmed in mouse models.

Summary The anti- $\alpha$-Gal immune response is complex and characterized by a unique feature. IgM and IgG antibodies have been found to confer protection against pathogens whereas the IgE-response to $\alpha$-Gal is detrimental and causes severe reactions upon exposure to mammalian meat and other products.
\end{abstract}

Keywords Alpha-gal $\cdot$ Carbohydrate $\cdot$ Food allergy $\cdot$ Red meat allergy $\cdot$ Tick

\section{Introduction}

The starting point for the discovery of the $\alpha$-Gal syndrome was the approval of cetuximab, a chimeric mouse-human IgG1 monoclonal antibody directed against the epidermal growth factor receptor, for the treatment of colorectal and squamous-cell cancer by the US Food and Drug Administration (FDA) in 2003. In contrast to previous

This article is part of the Topical Collection on Allergens

Christiane Hilger

christiane.hilger@lih.lu

1 Department of Infection and Immunity, Luxembourg Institute of Health (LIH), 29, rue Henri Koch,

L-4354 Esch-sur-Alzette, Luxembourg

2 Department of Dermatology, Eberhard Karls University Tübingen, Tübingen, Germany

3 Department of Dermatology and Allergy Biederstein, Technical University of Munich, Munich, Germany

4 Clinical Unit Allergology, Helmholtz Zentrum München, German Research Center for Environmental Health GmbH, Neuherberg, Germany experiences in the registration trials, a high rate of hypersensitivity reactions occurred upon the first application of cetuximab in the southeastern US federal states [1]. In the course of further examinations, Chung et al. identified specific IgE antibodies that surprisingly did not recognize a particular peptide sequence but a carbohydrate structure, galactose-alpha-1,3- galactose ( $\alpha$-Gal) [2]. $\alpha$-Gal is a common component in glycan structures of mammals. But there is an important exception due to a unique evolutionary event about 20-28 million years ago. In ancestral Old World monkeys and apes, the gene for the enzyme $\alpha-1,3-$ galactosyltransferase that is essential for the synthesis of $\alpha$-Gal was inactivated [3]. Therefore, humans and recent Old World primates do not express $\alpha$-Gal and this structure is highly immunogenic for them. In the late $80 \mathrm{~s}$, transplant immunology had already identified natural anti- $\alpha$-Gal antibodies, as IgG, IgM, and IgA isotypes, as the most abundant antibodies in humans. For xenotransplantation, i.e., transplantation of organs from pigs into humans, these antibodies represent a major immune barrier [3]. A new aspect of the $\alpha$-Gal immune response was the circumstance that an IgE isotype of anti- $\alpha$-Gal antibodies with a high anaphylactic potential had been found [4]. 


\section{a-Gal and Red Meat Allergy}

Upon examination of patients with anaphylaxis to cetuximab, Collins et al. discovered a new form of allergy to red meat in 2009 [5]. In contrast to common experience in food allergy, these allergic reactions have as unique feature a delayed onset of effects of 3-6 h after consumption of mammalian meat (Fig. 1). The clinical severity of these type-I reactions can vary and ranges from urticaria/angioedema to life-threatening anaphylaxis with hypotension, shock, and unconsciousness. The reason for this delay of onset is not yet understood, but an association with digestion processes, especially fat digestion, is assumed [6]. Clinical findings in oral challenges show [7•] that according to the concept of food-dependent exercise-induced anaphylaxis (FDEIA) [8], endogenous and exogenous factors (e.g. alcohol, physical exercise, non-steroid analgesic, infections, and menstruation) are able to enhance the allergic reaction to mammalian meat. This observation can explain why quite a lot of $\alpha$-Gal IgE-positive individuals have no evidence of allergic reactions to mammalian meat as their exposure is probably below the threshold for induction of symptoms in the absence of cofactors [9]. But these individuals are under potential risk to develop anaphylaxis upon exposure to a certain amount of $\alpha$-Gal in combination with relevant augmenting factors [9]. In foods, $\alpha$-Gal is not only found in meat products. Dairy products, like milk, cream, or cheese also contain small amounts of $\alpha$-Gal (Fig. 1). Gelatin is another source for $\alpha$-Gal and widely used in foods as gelling and thickening agent, for example in sweets, cake glace, or fat-reduced dairy products (Fig. 1) [10, 11••]. Accordingly, clinical observations indicate that these $\alpha$-Gal sources are tolerated in some $\alpha$-Gal allergic patients, but not in highly allergic individuals $[5,10,12]$. The consumption of mammalian innards, like pork kidney, takes on a special position in $\alpha$-Gal syndrome as symptoms often are more severe and occur more rapidly (Fig. 1). Upon consumption of pork kidney, an immediate onset of anaphylaxis instead of the typical delayed onset is regularly observed [13]. Therefore, innards are regarded as the most potential $\alpha$-Gal source. It is commonly assumed that this is linked to a higher content in $\alpha$-Gal in innards compared to muscle meat $[7 \cdot, 13]$. In Europe, $\alpha$-Gal syndrome patients are described, who only react after consumption of mammalian innards, but not after consumption of mammalian muscular meat [12]. Angiotensin I-converting enzyme (ACE I) and aminopeptidase N (AP-N), both highly glycosylated proteins of urogenital tissues, were identified as major IgE-binding molecules in pork kidney [14•]. The isolated proteins were able to induce basophil activation in patients with $\alpha$-Gal

\section{IgE-mediated}

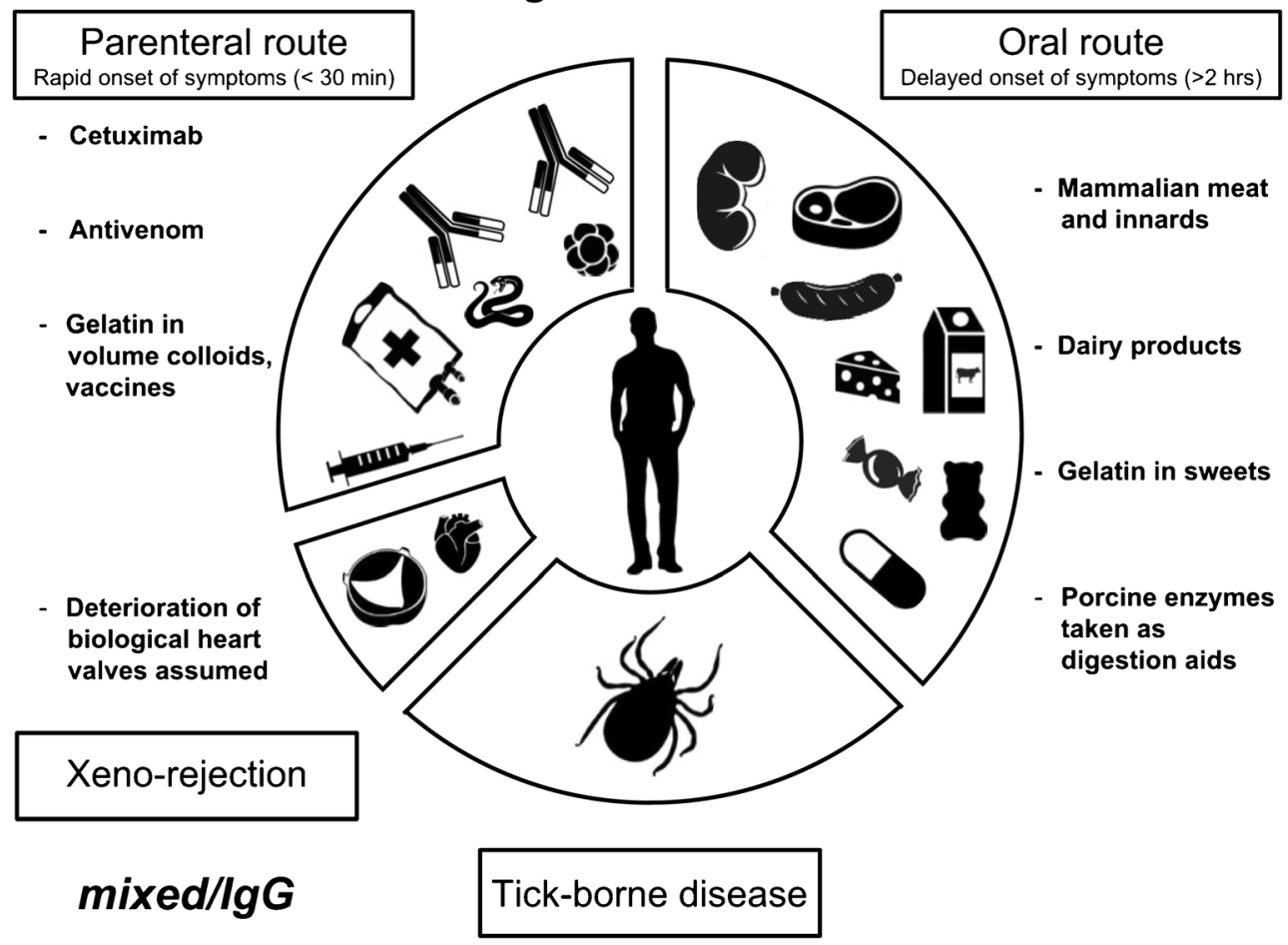

Fig. $1 \alpha$-Gal syndrome. The $\alpha$-Gal syndrome describes an IgE-mediated allergy to the disaccharide galactose- $\alpha$-1,3-galactose ( $\alpha$-Gal). Base arctick bites are assumed to be the most frequent and most important primary sensitization source to $\alpha$-Gal, and $\alpha$-Gal syndrome is the first allergy classified as tick-borne disease. Left upper arc — administration of drugs derived from mammalian cells and tissue (like cetuximab, antivenom, gelatin in colloids or vaccines) can induce drug allergy. Left lower arc - as part of xeno-rejection, deterioration of biological heart valves is assumed. Right arc-consumption of mammalian muscle meat and innards, but also dairy products, gelatin in sweets or porcine pancreatic enzymes in digestion aids can induce food allergy 
syndrome, and IgE-binding was shown to be directed to $\alpha$-Gal epitopes carried by both proteins. Two other studies identified several IgE-binding proteins carrying $\alpha$-Gal epitopes in beef meat by two-dimensional gel electrophoresis and peptide mass fingerprinting techniques $[15,16]$.

\section{The Association with Ticks}

The geographic outlined accumulation of hypersensitivity in the southeastern US federal states, and the fact that patients developed anaphylaxis on first contact with cetuximab indicated that the patients were presensitized and inducing environmental factors were searched for [17]. A report from Australia, describing a correlation between allergic local reactions to tick bites and allergy to red meat, brought ticks in the focus of US researchers $[17,18]$. The epidemiological matching of occurrence of anaphylaxis to cetuximab with an endemic area of the rocky-mountain spotted fever, a tick-borne disease mainly transmitted by Amblyomma americanum, supported the tick-hypothesis. Today, we know that in addition to Amblyomma spp., various other tick genera, like Haemaphysalis spp. and Ixodes spp., are involved as well [19, 20] (Fig. 1). The presence of $\alpha$-Gal in ticks could be demonstrated by ELISA, immunoblotting techniques, and immunohistochemical staining in various tick species [19, 20]. Recently, Araujo et al. showed that $\alpha$-1,3-galactosyltransferase-deficient mice could be sensitized to $\alpha$-Gal by tick saliva of Amblyomma sculptum $[21 \bullet \bullet$. Therefore, it is commonly assumed that tick bites are the most frequent and most important primary sensitization source to $\alpha$-Gal and $\alpha$-Gal syndrome is the first allergy classified as tick-borne disease. Recently, chiggers, mites of the Trombiculidae family at their larval stage, have been reported to be associated with sensitization to $\alpha-\mathrm{Gal}$ and delayed allergy to red meat in three patients [22]. Ticks do not only serve as a vector for sensitization, but tick bites can also be associated in some cases with anaphylaxis. Tickinduced anaphylaxis is most often observed in Australia during removal of ticks [23]. Local allergic reactions around the bites, presenting as erythematous papules or plaques itching for more than 10 days, are regularly observed in $\alpha$ Gal-sensitized individuals after tick bites [17]. While initially the $\alpha$-Gal syndrome was seen as local allergy in the southeastern US federal states, we know now that the $\alpha$-Gal syndrome occurs on all continents and has a global health impact.

As anti- $\alpha$-Gal IgE is an environmental type-I sensitization, its prevalence in a human population depends on the degree of exposure to ticks. In an epidemiological survey among hunters and forest workers, a high prevalence of type-I sensitizations to $\alpha$-Gal of $35.0 \%$ was observed ( $\alpha$-Gal-sIgE levels $\geq 0.10 \mathrm{kUA} / \mathrm{L}$ ) [24•]. A history of $\alpha$-Gal syndrome was found in $8.6 \%$ of the $\alpha$-Gal-sIgE-positive participants with levels $\geq$ $0.35 \mathrm{kUA} / \mathrm{L}[24 \bullet]$. In rural European areas, the prevalence of type-I sensitizations to $\alpha$-Gal can be up to $24.7 \%$ ( $\alpha$-Gal-sIgE levels $\geq 0.10 \mathrm{kUA} / \mathrm{L}$ ) [25]. In contrast, in general adult populations living in an urban environment, the prevalence ranges between 5.5 and $8.1 \%(\alpha-$ Gal-sIgE levels $\geq 0.10 \mathrm{kUA} / \mathrm{L})$ [26]. This high prevalence of $\alpha$-Gal-sIgE levels challenges the diagnosis of the $\alpha$-Gal syndrome. Skin prick tests using meat extracts often give false negative results whereas prick-toprick tests with pork or beef kidney or intradermal testing with gelatin colloid are sensitive, but elaborate in handling $[5,7 \bullet]$. $\alpha$-Gal-sIgE levels are not predictive for the clinical relevance regarding the consumption of mammalian meat or $\alpha$-Gal containing drugs $[5,7 \bullet, 11 \bullet \cdot]$. Therefore, diagnosis of the $\alpha$ - Gal syndrome strongly relies on clinical history and food challenges are warranted to determine the clinical relevance [11, $27 \bullet$. A recent study has shown that the basophil activation test is of added value for differentiation between patients with $\alpha$ Gal syndrome and asymptomatic $\alpha$-Gal sensitization [28•].

The closest human carbohydrate to $\alpha$-Gal is blood antigen $\mathrm{B}$, a fucosylated Gal $\alpha 1 \rightarrow 3 \mathrm{Gal}$ epitope. The proposed hypothesis that individuals with blood type B have reduced susceptibility to type I sensitization to $\alpha-\mathrm{Gal}$ and reduced $\alpha$-GalsIgE levels is controversial. The assumption that individuals with blood type B have a lower susceptibility to develop typeI-sensitizations to $\alpha$-Gal is mainly supported by the case series of Hamsten et al. where the prevalence of B blood types was 3.6-fold lower than expected in comparison to the Swedish general population [29]. In an epidemiological survey in a highly tick-exposed population, this finding could not be reproduced [30]. In addition, Galili et al. could not find quantitative differences of natural anti- $\alpha-G a l$ IgG antibodies in different human blood groups [31].

\section{Evolutionary Aspects of the Human Anti-a-Gal Response}

The $\alpha$-1,3-galactosyltransferase $(\alpha 1,3 \mathrm{GT})$ gene named GGTA1 is present in all mammals, but in humans, apes, and Old World Monkeys, it is inactivated by frame-shift mutations that truncate the expressed protein and abolish its catalytic activity [32]. $\alpha 1,3 \mathrm{GT}$ catalyzes the transfer of a galactose residue with an $\alpha-1,3$ linkage, on terminal lactosaminide (Gal- $\beta$-1,4-GlcNAc-R) disaccharide on glycoproteins and glycolipids, generating terminal $\alpha$-Gal. The gene GGTA1 seems to have emerged early during mammalian evolution since it is also active in marsupials. It is suggested that the inactivation of the gene was the result of a strong evolutionary pressure. Primates with an inactive gene would not synthesize $\alpha$-Gal epitopes but would be able to develop anti- $\alpha$-Gal antibodies which would have been of advantage in fighting pathogens expressing $\alpha$-Gal. It has indeed been shown that 
enveloped viruses produced in animal cells or human cells engineered to contain active $\alpha 1,3 \mathrm{GT}$ contain multiple $\alpha$-Gal epitopes on their surface, rendering them more sensitive to lysis by human anti- $\alpha$-Gal antibodies and complement [33, 34]. Earlier observations have reported that patients with leishmaniasis and patients with Chagas' disease had markedly elevated titers of anti- $\alpha$-Gal antibodies, raising the possibility of immunogenic stimulation by the respective parasites [35]. The presence of $\alpha$-Gal epitopes on Trypanosoma cruzi, Leishmania braziliensis and L. mexicana parasites was confirmed by antibody and lectin staining, inhibition, and deglycosylation experiments [35]. Thus, the human anti- $\alpha$-Gal antibody response may contribute to the natural defense against various parasites (Fig. 2).

A recent study addressed this question by using an $\alpha 1,3$ GT knockout (Ggtal KO) mouse model [37••]. Mice were inoculated with the human pathobiont $E$. coli $\mathrm{O} 86: \mathrm{B} 7$ which has been shown to induce anti- $\alpha-G a l$ IgG and IgM antibodies in Ggtal KO mice [38]. Circulating anti- $\alpha-\mathrm{Gal}$ antibodies were able to target Plasmodium sporozoites immediately after inoculation in the skin and conferred protection from malaria transmission. In line with these results, the authors showed that in malaria-endemic areas, high levels of anti- $\alpha$-Gal IgM antibodies are associated with a decreased risk of malaria transmission [37••]. Similar results were obtained in a study by Cabezas-Cruz and colleagues [39]. The levels of anti- $\alpha-$ $\mathrm{Gal} \mathrm{IgM}$ and $\mathrm{IgG}$ antibodies were higher in healthy individuals than in individuals infected with Plasmodium falciparum or Mycobacterium tuberculosis [39]. These findings raise the question if vaccination approaches including the $\alpha$-Gal epitope could be successful in conferring protection to malaria and possibly to other vector-borne diseases [40]. Two $\alpha$-Gal vaccines against Leishmania infection have been tested in the Ggta1 KO mouse model. Both approaches, a neoglycoprotein carrying synthetic $\alpha$-Gal epitopes and a virus-like particle carrying multiple $\alpha$-Gal epitopes, were able to significantly reduce parasite burden in infected mice [41, 42].

Anti- $\alpha$-Gal IgG antibodies are highly abundant in human serum, estimated at 30 to $100 \mu \mathrm{g} / \mathrm{ml}$ [43]. They cross the placenta and are detected in high titers in cord blood. Antibody levels are at lowest between 3 and 6 months, then increase gradually and reach titers comparable to adults between 2 and 4 years [44]. This high level of anti- $\alpha$-Gal antibodies at early age raises the question about the source of the antigenic stimulus. Earlier studies have shown that human anti- $\alpha$-Gal antibodies interact with a variety of Escherichia coli, Klebsiella, and Salmonella strains [45]. The fact that some of the E. coli and Klebsiella strains were obtained from normal human stool samples supports the hypothesis that bacteria of the intestinal microbiome would provide the antigenic stimulus for a continuing production of anti- $\alpha$-Gal antibodies (Fig. 2). The spectrum of anti-Gal specificity however is dependent on the individual's blood type. The $\alpha$-Gal epitope is
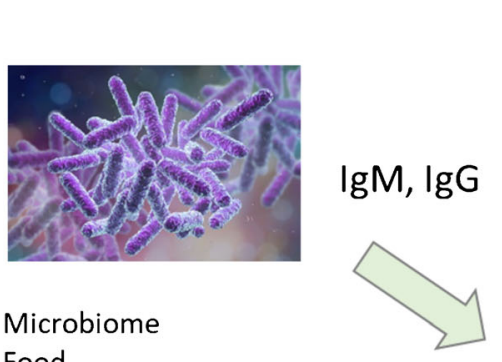

Microbiome

Food

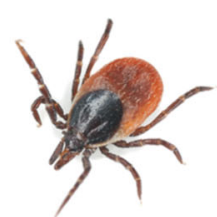

$\lg \mathrm{E}$

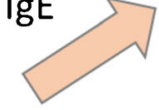

Ticks

Amblyomma americanum, $A$. cajennese

Ixodes ricinus, I. holocyclus

Haemaphysalis longicornis

Fig. 2 Anti- $\alpha$-Gal antibodies: friend or foe? It is commonly assumed that IgM and IgG antibodies are generated by continuous stimulation by the intestinal microbiome and probably also by food. Bites of different hard ticks have been associated with the production of $\operatorname{IgE}$ antibodies directed to $\alpha$-Gal. Whereas IgE antibodies are detrimental and responsible for anaphylactic reactions to food and drugs, IgG and $\operatorname{IgM}$ antibodies seem

\section{$\alpha$-gal epitope}

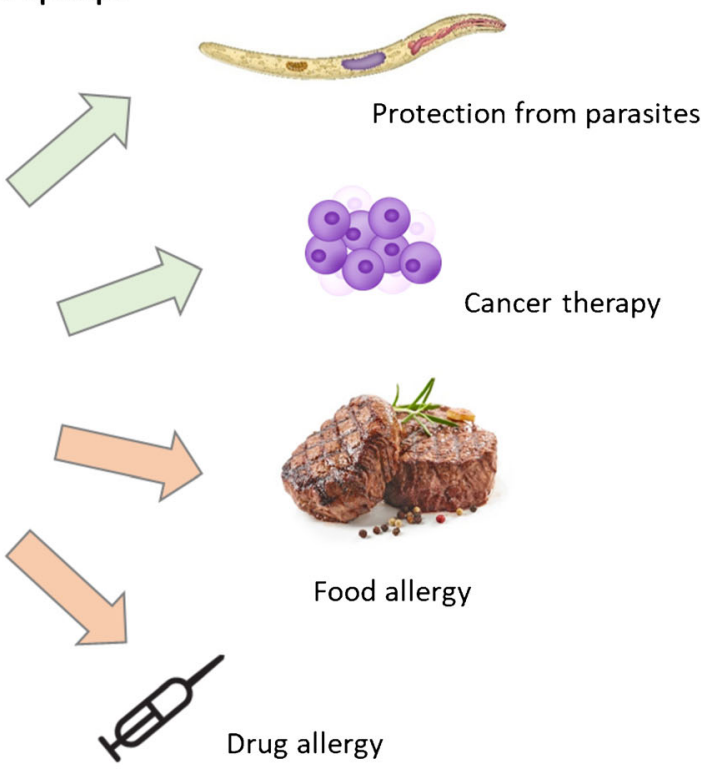

to play a role in protection from parasites and possibly other pathogens. The insertion of $\alpha$-Gal glycolipids into tumor cells has been investigated in pre-clinical models of cancer immunotherapy. A typical $\alpha-\mathrm{Gal}$ carbohydrate structure as e.g. present on cetuximab [36] is shown above the antibody. Yellow circle: galactose; green circle: mannose; blue square: $\mathrm{N}$-acetylglucosamine; red triangle: fucose 
very similar to the B blood group antigen where a fucose is attached to the second galactose (Gal- $\alpha 1,3$ (Fuc- $\alpha 1,2)-G a l)$. Anti- $\alpha$-Gal antibodies purified from human $\mathrm{O}$ or A serum also recognized the $\mathrm{B}$-antigen. On the contrary, $\mathrm{IgG}$ isolated from donors with $\mathrm{AB}$ or $\mathrm{B}$ blood group are not able to recognize the $B$-antigen because of immune tolerance and they have a more specific $\alpha$-Gal response [46].

\section{a-Gal Is Present in Many Non-Food Sources}

The list of drugs obtained from mammalian cells or tissues with specific risks for $\alpha$-Gal sensitized individuals has increased over the years. Genetically engineered therapeutic antibodies play an important role in medicine, namely oncology or rheumatology. Luckily, with the exception of cetuximab, till now, no other therapeutic antibody conferring a comparable risk to $\alpha$-gal sensitized individuals was found (Fig. 1) [47].

The $\alpha$-Gal epitope of cetuximab is located in the Fab region which is of mouse origin [47]. $\alpha$-Gal has also been identified in the Fc region of cetuximab and other therapeutic antibodies produced in mammalian cells such as SP2/O and NS0, but these were not recognized by IgE antibodies of $\alpha$ Gal sensitized individuals [47]. On mAbs produced in $\mathrm{CHO}$ cells, $\alpha$-Gal was undetectable. The risk of an anaphylactic reaction to those antibodies and to antibodies carrying the $\alpha$ Gal epitope on the Fc part of the antibody was estimated to be very low. However, a recent case reported an anaphylactic reaction to infliximab, a monoclonal antibody carrying an $\alpha$ Gal epitope on the Fc part and produced in SP2/0 cells [48].

The $\alpha$-Gal epitope is also present on other pharmaceuticals and products of animal origin such as gelatin, antivenoms, and bioprosthetic heart valves. Gelatin is obtained by hydrolysis of collagen, a product obtained from bones and connective tissue of animals. The product is not only used in processed food and sweets such as desserts and gummy bears, but it is also used in vaccines and in gelatin colloids as plasma expander. The $\alpha$-Gal epitope was detected on the collagen a-1 (VI) chain and in gelatin colloids $[11 \bullet \bullet, 16]$. Clinical reports include allergic reactions to gummy bears, a vaginal gelatin capsule, and vaccines with high gelatin content such as zoster vaccine which contains $15.58 \mathrm{mg}$ per $0.65 \mathrm{ml}$ dose [10, 49-52]. However, not all patients with $\alpha$-Gal syndrome react to zoster vaccine $[52,53]$. Allergic symptoms upon intravenous administration of gelatin colloids, intramuscular injection of vaccines, or intravaginal application of gelatin capsules appear within the first $30 \mathrm{~min}$ whereas upon oral administration of gelatin, symptoms appear delayed [10, $11 \bullet \bullet, 49-51]$.

Antivenoms are polyclonal antibody preparations obtained by immunization of horse or sheep with snake venom. In order to reduce the total load of administered protein, some antivenom formulations are enzymatically digested to produce divalent or monovalent immunoglobulin fragments ( $F(a b ') 2 / F a b)$. The Fab fragments of such preparations have been shown to carry the $\alpha$-Gal epitope [54], and a case of hypersensitivity has been reported recently in an $\alpha$-Gal-sensitized patient [55]. Recently, porcine enzyme preparations taken orally for digestion aid against bloatedness, flatulence, and stomach pain as dietary supplement (pepsin) or as drug for treatment of exocrine pancreatic insufficiency (pancreatic enzymes) were identified as potential $\alpha$-Gal source [56] (Fig. 1).

The $\alpha$-Gal syndrome has been evoked in three cases of cattle workers who presented with allergic symptoms after assisting the veterinarian during calving [57], representing the first report on $\alpha$-Gal as occupational and respiratory allergen. $\alpha$-Gal was detected in the amniotic fluid. Two of the workers had mainly contact urticaria limited to exposed areas of the skin, while the third one also experienced dyspnea, probably by inhalation of amniotic fluid components.

Bioprosthetic heart valves are of bovine or porcine origin. Glutaraldehyde fixation is used to ensure biocompatibility of the treated xenogeneic tissue. A study conducted by Naso and co-authors on commercially available bioprosthetic valves showed that for some products, not all $\alpha$-Gal epitopes were masked by the procedure and were still detectable [58]. An association between IgE antibodies to $\alpha$-Gal and a premature degeneration of bioprosthetic aortic valves is postulated in two patients who developed an allergy to $\alpha$-Gal [59]. Specific IgE antibodies directed to $\alpha$-Gal have also been linked recently to an increased burden of atherosclerosis and to plaques with less stable characteristics [60]. The authors hypothesize that the $\alpha$-Gal epitope which is also present on mammalian glycolipids could increase the inflammatory response to dietary glycolipids in $\alpha$-Gal sensitized patients. To date, the actual risk of $\alpha$-Gal-sensitized patients who would require bioprosthetic heart valves or who develop an $\alpha$-Gal syndrome after xenotransplantation is not known and certainly requires further monitoring.

The abundance of natural human anti- $\alpha$-Gal IgM and IgG antibodies has prompted research on their clinical application in cancer therapy [61] (Fig. 2). Glycolipids isolated from rabbit red cell membranes were injected into solid tumors. The insertion of the glycolipids into tumor cell membranes resulted in the presentation of multiple $\alpha$-Gal epitopes on tumor cells. In vitro studies showed that these cells were lysed in the presence of complement and anti- $\alpha$-Gal antibodies. In an Ggtal KO mouse model, injection of glycolipids into melanoma tumors resulted in complement-mediated and antibodydependent cell-mediated tumor regression. The local destruction of tumor cells resulted in intratumoral inflammation and a systemic anti-tumor immune response [62]. A phase $1 / 2 \mathrm{a}$ trial for solid tumor immunotherapy using a synthetic $\alpha$-Gal 
glycolipid, AGI-134, has been initiated by BioLineRx Ltd. (Tel Aviv, Israel) (https://clinicaltrials.gov/ct2/show/ NCT03593226?term=AGI-134\&rank=1 ).

\section{Investigating Pre-Clinical Models to Better Understand Sensitization to a-Gal and Anaphylaxis to Red Meat}

The absence of $\alpha$-Gal is a prerequisite to allow percutaneous sensitization in humans. Mice, in contrast, express a fully functional $\alpha-1,3$-galactosyltransferase and murine proteins abundantly carry $\alpha$-Gal residues [63-65]. Consequently, $\alpha$-Gal is a self-antigen in mice and wild-type mice develop neither $\operatorname{IgG}$ nor IgE directed to $\alpha$-Gal [66]. In contrast, the human immune system recognizes $\alpha$-Gal as non-self molecule, which consequently is capable to trigger immune reactions resulting in the production of anti- $\alpha$-Gal IgG or even $\alpha$-Gal specific IgE and allergy. While immune recognition of non-self proteins is well understood as is the cascade of events mounting immune responses of different qualities within the innate and adaptive immune system, characterization of immune check points and consequences in response to non-self carbohydrates is less well characterized. Thus, analyzing sensitization to $\alpha$-Gal and anaphylaxis to red meat will also shed light on immune consequences following exposure to non-self carbohydrates and investigating pre-clinical models has proven to be adequate to identify underlying immune mechanisms. To this end, investigating mice deficient in $\alpha$-1,3-galactosyltransferase is a suitable approach.

The abundance of IgG antibodies directed to $\alpha$-Gal in human sera, described in 1983 [67], could not be associated with any disease or even symptoms. However, in 1993, Galili et al. [68], Cooper et al. [69], and Sandrin et al. [70, 71] published that anti- $\alpha$-Gal antibodies in humans are associated with hyperacute graft rejection in xenotransplantation, e.g., from pigs (carrying $\alpha$-Gal) to primates (deficient in $\alpha$-Gal). Therefore, to understand the role of $\alpha$-Gal antibodies and possibly overcome $\alpha$-Gal-dependent hyperacute graft rejection, two mouse strains were generated, in 1995 by Thall et al. [64] and in 1996 by Tearle et al. [65]. Both targeted electroporated 129/sv embryonic stem cells with a construct in which the exon 9, containing almost the entire $\alpha-1,3$-galactosyltransferase gene catalytic domain, had been disrupted by insertion of a neomycin resistance cassette. Effectively targeted embryonic stem cells then were injected into blastocysts to obtain either CBA $\times$ $\mathrm{C} 57 \mathrm{~B} 16$ [65] or $129 \mathrm{SV} \times \mathrm{C} 57 \mathrm{BL} / 6 \mathrm{~J} \times \mathrm{DBA} / 2 \mathrm{~J}$ chimeric mice [64]. $\alpha$-1,3-galactosyltransferase knockout mice (Ggta1 KO) were reported to be healthy despite the development of cataracts, impaired glucose tolerance, a decreased insulin sensitivity, and a more aggressive behavior $[64,65,72,73]$. By either using an IB4 lectin staining on splenocytes [65] or anti- $\alpha-\mathrm{Gal}$ antibody staining on vascular endothelial cells, both strains were shown to not express $\alpha$-Gal and to not spontaneously produce anti- $\alpha$-Gal antibodies [64]. Both strains were used to effectively prove that indeed high anti- $\alpha-\mathrm{Gal} \operatorname{IgG}$ and IgM antibodies mediate hyperacute graft rejection in mice within hours [74] to 8-13 days [74, 75]. In contrast, recipient Ggta 1 KO mice with low anti- $\alpha$-Gal antibody titers showed a prolonged graft survival of $>90$ days [75]. Although Ggta1 KO mice spontaneously develop anti- $\alpha$-Gal antibodies, titers remain lower than in humans $[66,75,76]$. To increase antibody titers to levels comparable to those observed in humans, a number of sensitization protocols had been developed. Many different $\alpha$-Gal carrying back-bone structures were proven to be effective like KLH-Gal, Leishmania major promastigotes, or rabbit red blood cell membranes [66, 74, 75]. A high density of $\alpha$-Gal residues and most effective sensitization was observed using rabbit red blood cell membranes intraperitoneally injected together with complete or incomplete Freund's adjuvant (CFA or IFA respectively) [75]. The resulting $\alpha$-Gal-specific antibodies (approximately $0.6 \%$ of total serum $\operatorname{IgG}$ ) were shown to be comparable to human $\alpha$ Gal-specific IgG antibodies regarding avidity $(30 \mathrm{nM}$ in mice, $6 \mathrm{nM}$ in humans) and affinity (15 $\mathrm{mM}$ in mice, $50 \mathrm{mM}$ in humans). Isotype distribution among antibody subclasses following $\alpha$-Gal-specific sensitization in Ggta1 KO mice was also comparable to those reported for humans [75]. Investigating the density of $\alpha$-Gal residues revealed striking differences between different tissues and species. Obviously, tissues most extensively analyzed are those from pigs [77] and especially rich in $\alpha$-Gal are glomerulus endothelia and proximal and distal tubules in the kidney, bronchial epithelia, pancreas lobular ducts, and vascular endothelia [78]. Thus, these analyses identified pork kidneys as rich in $\alpha$-Gal, already indicating their relevance for red meat allergy discovered much later $[7 \bullet, 9,10,12,14 \bullet, 24 \bullet, 28 \bullet, 54,79,80]$. Interestingly but not surprisingly, $\alpha$-Gal is also expressed in the thymus of $\alpha$-Gal competent species [81]. Thymic expression of self antigens confers central immune tolerance by deletion of auto-reactive $T$ cells and generation of thymic tTreg cells [82]. Accordingly, it has been postulated that all mammals synthesizing $\alpha$-Gal epitopes should be tolerant to it and consequently not producing anti-Gal antibodies [83]. Therefore, the fact that Ggtal KO mice spontaneously develop anti- $\alpha$-Gal antibodies additionally confirms that they are at least not fully tolerant as orchestrated by the thymus and are capable to develop immune responses to non-self $\alpha$-Gal ideally mimicking the situation in humans. Most interestingly, in Ggta1 KO mice like in humans, the initial immune response to $\alpha$-Gal with induction of specific IgM and $\operatorname{IgG}$ antibodies is not associated to the development of any detectable dysfunction, inflammation, or disease. This is vitally important in organisms lacking intrinsic $\alpha$-Gal production, since $\alpha$-Gal is nearly ubiquitously expressed in the environment. Regarding $\alpha$-Gal, there is strong evidence that cutaneous exposure to $\alpha$ - 
Gal in humans due to repeated tick bites is able to initiate a switch to the production of $\alpha$-Gal-specific IgE. Until now, data on allergy to $\alpha$-Gal in the mouse model are very limited. However, effective percutaneous sensitization to $\alpha$-Gal in Ggta1 KO mice has been reported by Araujo et al [21••]. The authors either subcutaneously injected $\alpha$-Gal bound to "bacteriophage Qb-virus like particles" (Qb-VLPs), each displaying 540 copies of $\alpha$-Gal on its surface, once weekly for 4 weeks; injected tick saliva following the same protocol or placed one male and one female tick in parallel on the back of a mouse for 9 days using a feeding chamber. Detection of anti- $\alpha$-Gal antibodies in mouse serum by ELISA using the Qb-VLPs or tick saliva as $\alpha$-Gal source for coating clearly showed a relative strong induction of $\alpha$-Gal-specific IgE following tick feeding and a less strong effect following subcutaneous injection of tick saliva. Interestingly, subcutaneous injection using the $\alpha$-Gal-Qb-VLPs alone triggered $\alpha$-Galspecific IgG but no IgE. The authors suggests that "the salivary protein(s) bearing the $\alpha$-Gal-like antigen(s) might modulate the immune response in a different way than VLP display." Another reason might be an intrinsic Th2 immunitypromoting adjuvant function of tick saliva components. Indeed, Ohta et al. were able to prove that tick bites in mice induce skin resident IL-3 + CD4+ memory T cells predominantly being CD44 + CD62L - CD69+ [84••]. After an initial tick bite, these cells could be detected even in previously uninfested skin distant from the original feeding site and IL3 production by these cells was proven to be necessary for the rapid recruitment of basophils to the site of a second tick bite. As basophils were repeatedly shown to be major IL-4 producers $[85,86]$, this mechanism might at least in part explain the Th2 triggering capacity of repeated tick bites and the consecutive production of a-Gal-specific IgE.

\section{Immune Responses to a-Gal in Comparison to Other Carbohydrates}

Carbohydrate determinants can be found on almost all proteins and belong to the most abundant immune determinants [87]. Well-known examples are the blood group antigens or bacterial polysaccharides used as vaccination antigens, e.g., as part of the Haemophilus influenza type b vaccine [87]. However, until the identification of the delayed type I allergy to red meat caused by IgE directed to $\alpha$-Gal, IgE recognizing carbohydrate determinants has been interpreted as mostly clinically irrelevant for type I allergy. Carbohydrate moieties as possibly relevant allergens for the first time got attention in the 1980s when Aalberse et al. reported that $\operatorname{IgE}$ antibodies from patients cross-react with vegetable foods, Hymenoptera venoms, and pollen, an effect which could be abolished by treatment with the strong oxidant periodate [88]. They concluded that the observed cross-reactivity is due to carbohydrates which they termed "carbohydrate crossreactive determinants" (CCDs). Their findings could be confirmed by other groups using bromelain, a small glycopeptide isolated from the pineapple stem, which is particularly suitable because the peptide contains only two to four amino acids which are not likely to act as an antigen on their own [89]. Relevant as CCDs, since ubiquitously expressed in the environment but not as part of mammalian glycoproteins, are xylose, found in plants and parasitic worms, and core-3linked fucose, also synthesized in insects, containing $\mathrm{N}$ glycans [87]. However, interest in carbohydrate epitopes remained low, since they are usually of a low clinical significance without anaphylactic potential [90]. Next to $\alpha$-Gal, only very few and much less well investigated and understood putatively clinically relevant carbohydrate allergens exist. Initially, only in Japan anaphylactic reactions to galacto-oligosaccharides (GOSs) have been reported. GOSs vary in length and type of linkage between the monomers but typically consist of a chain of 2-6 mostly galactose molecules and a terminal glucose [91]. Originally, in workers on Japanese oyster farms, a form of occupational asthma has been described for which a number of different oligosaccharitols isolated from the $\mathrm{H}$-antigen of the sea squirt were identified as causative allergens [92, 93]. Interestingly, in these same oyster farm workers, later on a series of immediate-type allergic reactions after consuming a lactic acid beverage popular in Japan has been observed [94]. Jyo et al. could show that all patients had been exposed to the sea squirt working on oyster farms, that $1-3$ or $1-6$ linked GOS consisting of four saccharides, as identified in the anaphylaxis-causing beverage, induced positive scratch tests and histamine release assay and that the IgEantibodies directed to GOS were also cross-reactive to sea squirt antigens [94]. Most interestingly, since GOS in the meantime are often used as probiotic supplements in beverages all over the world, cases of GOS allergy triggered by other specific GOS than the aforementioned following ingestion of infant milk products or commercially available milk drinks $[95,96]$ have been published. Anaphylactic reactions to other foods have also been reported to depend on glycoprotein allergens; however, the data basis is mostly insufficient $[97,98 \bullet \bullet]$. The knowledge about the basic mechanisms underlying immune reactions to carbohydrates is limited. Regarding immune reactions to proteins, we know that they are intracellularly cleaved and peptide fragments presented via MHCII together with costimulatory molecules then activate T cells which on their part can promote the activation of B cells. Although we do not know it for sure, at least regarding glycan moieties of glycoproteins, this mechanism most likely also applies to carbohydrate allergens. However, B1 B cells, which can be stimulated and produce antibodies without getting an activation signal from T helper cells, might also be involved. To disclose the mechanisms involved specifically in the immune reaction to 
$\alpha$-Gal, Cretin et al. used Ggta1/T cell receptor beta chain $(\mathrm{TCR} \beta)$ double $\mathrm{KO}$ mice to investigate if Tcells are involved in the induction of anti- $\alpha$-Gal antibodies [76]. They observed an age-dependent increase in anti- $\alpha$-Gal IgG titers in Ggta 1 KO mice but not in Ggta1/TCR $\beta$ double KO.

Likewise they could booster anti- $\alpha$-Gal IgG titers in Ggta1 KO mice by immunization with pig cells but not in Ggta1/TCR $\beta$ double KO. In addition, treatment with anti-CD40L antibodies, which inhibits $\mathrm{T}$ cell-dependent $\mathrm{B}$ cell maturation and class switching, before immunization with pig cells could inhibit sensitization to $\alpha$-Gal in Ggta1 KO mice. At least regarding $\alpha$-Gal, these data indicate an important role for $\mathrm{T}$ cells also in immune reactions to carbohydrate allergens. However, for a fundamental and more general understanding of the mechanisms and cell types involved in immunity to carbohydrate allergens, further studies are urgently needed.

\section{Conclusion}

Immune consequences of the exposure to non-self carbohydrates is a very important focus of research, since the cascade of immune events is much less well defined compared to immune reactions to non-self proteins. However, the description and in-depth characterization of delayed type I immediate reactions to red meat and offal demonstrates the relevance and medical consequences that the exposure to non-self carbohydrates may have. Interestingly, the exposure to non-self carbohydrates in the gastrointestinal tract apparently fails to induce adverse immune reactions while the repetitive cutaneous exposure to $\alpha$-Gal through tick bites may induce $\alpha$-Galspecific IgE antibodies and a clinically relevant allergy to $\alpha$ Gal. Many sources contain $\alpha$-Gal such as $\alpha$-Gal containing drugs, food, or volume colloids and in susceptible patients, an exposure can elicit type I allergic reactions. Importantly, socalled co- or augmentation factors may modulate the susceptibility and severity of the anaphylactic reactions. Taken together, the field warrants further attention in regard to increase our mechanistic understanding, to improve patient risk assessment, patient care, but also to possibly introduce prevention of disease development. To this end, a deeper look into (i) tick biology and (ii) the transmission of adjuvants and (iii) $\alpha$-Gal containing cells, proteins, and lipids; (iv) the translation of tick-derived information into immune consequences within the skin; (v) the establishment of IgE production; and (vi) the consecutive regulation of anaphylactic responses following exposure to $\alpha$-Gal are categories of investigations necessary and each asks for detailed analyses and single-step characterization. Based on these analyses, new concepts will arise that not only allow us to better understand the "immune digestion" of $\alpha$-Gal containing proteins and lipids but also to extrapolate the basic findings to carbohydrate immunology per se in regard to its recognition, carbohydrate-induced immune responses, the regulation of immune tolerance towards carbohydrates, and the longevity of carbohydrate-directed immune responses.

Funding This work was supported with a bilateral funding from the Luxembourg National Research Fund (FNR), project C17/BM/ 11656090, and the Deutsche Forschungsgemeinschaft (DFG), project BI 696/12-1 and FI 2226/2-1, as well as by grants from the DFG (SFB 1371, SPP1394 BI 696/5-2).

\section{Compliance with Ethical Standards}

Conflict of Interest Dr. Biedermann reports grants from SanofiGenzyme and personal fees from Alk-Abelló, Astellas, Bencard, Biogen, Celgene Janssen, Leo, Mylan, MSD Novartis, Phadia-Thermo Fisher, and Sanofi-Regeneron, outside the submitted work. The authors declare no conflicts of interest relevant to this manuscript.

Human and Animal Rights and Informed Consent This article does not contain any studies with human or animal subjects performed by any of the authors.

Open Access This article is distributed under the terms of the Creative Commons Attribution 4.0 International License (http:// creativecommons.org/licenses/by/4.0/), which permits unrestricted use, distribution, and reproduction in any medium, provided you give appropriate credit to the original author(s) and the source, provide a link to the Creative Commons license, and indicate if changes were made.

Publisher's Note Springer Nature remains neutral with regard to jurisdictional claims in published maps and institutional affiliations.

\section{References}

Papers of particular interest, published recently, have been highlighted as:

- Of importance

- Of major importance

1. O'Neil BH, Allen R, Spigel DR, Stinchcombe TE, Moore DT, Berlin JD, et al. High incidence of cetuximab-related infusion reactions in Tennessee and North Carolina and the association with atopic history. J Clin Oncol. 2007;25:3644-8.

2. Chung CH, Mirakhur B, Chan E, Le Q-T, Berlin J, Morse M, et al. Cetuximab-induced anaphylaxis and $\mathrm{IgE}$ specific for galactose-\{alpha\}-1,3-galactose. N Engl J Med. 2008;358:110917.

3. Galili U, Clark MR, Shohet SB, Buehler J, Macher BA. Evolutionary relationship between the natural anti-Gal antibody and the Gal alpha $1-3 \mathrm{Gal}$ epitope in primates. Proc Natl Acad Sci U S A. 1987;84:1369-73.

4. Commins SP, Jerath MR, Platts-Mills T. The glycan did it: how the $\alpha$-gal story rescued carbohydrates for allergists - a US perspective. Allergo J Int. 2016;25:44-8.

5. Commins SP, Satinover SM, Hosen J, Mozena J, Borish L, Lewis $\mathrm{BD}$, et al. Delayed anaphylaxis, angioedema, or urticaria after 
consumption of red meat in patients with $\operatorname{IgE}$ antibodies specific for galactose-alpha-1,3-galactose. J Allergy Clin Immunol. 2009;123: 426-33.

6. Wilson JM, Platts-Mills TAE. The oligosaccharide galactose- $\alpha-1,3-$ galactose and the -gal syndrome: insights from an epitope that is causal in immunoglobulin E-mediated immediate and delayed anaphylaxis. EMJ Allergy Immunol. 2018;3:89-98.

7. Fischer J, Hebsaker J, Caponetto P, Platts-Mills TA, Biedermann T. Galactose-alpha-1,3- galactose sensitization is a prerequisite for pork-kidney allergy and cofactor-related mammalian meat anaphylaxis. J Allergy Clin Immunol. 2014;134:755-759.e751 Characterizes a German cohort with $\alpha$-Gal allergy, describes that immediate elicitation of type I symptoms occurs when pork kidney is consumed, and that $\alpha$-Gal allergy is susceptible to augmentation of symptoms by co-factors.

8. Wolbing F, Fischer J, Koberle M, Kaesler S, Biedermann T. About the role and underlying mechanisms of cofactors in anaphylaxis. Allergy. 2013;68:1085-92.

9. Fischer J, Biedermann T. Delayed immediate-type hypersensitivity to red meat and innards: current insights into a novel disease entity. J Dtsch Dermatol Ges. 2016;14:38-44.

10. Caponetto P, Fischer J, Biedermann T. Gelatin-containing sweets can elicit anaphylaxis in a patient with sensitization to galactosealpha-1,3-galactose. J Allergy Clin Immunol Pract. 2013;1:302-3.

11.• Mullins RJ, James H, Platts-Mills TA, Commins S. Relationship between red meat allergy and sensitization to gelatin and galactosealpha-1,3-galactose. J Allergy Clin Immunol. 2012;129:13341342.e1331 Evaluation of the clinical significance of sensitization to gelatin. Most patients allergic to red meat are sensitized to gelatin, but only a subset will report reactions to intravenous (and sometimes oral) gelatin.

12. Fischer J, Yazdi AS, Biedermann T. Clinical spectrum of alpha-Gal syndrome: from immediate-type to delayed immediate-type reactions to mammalian innards and meat. Allergo J Int. 2016;25:5562 .

13. Morisset M, Richard C, Astier C, Jacquenet S, Croizier A, Beaudouin E, et al. Anaphylaxis to pork kidney is related to $\operatorname{IgE}$ antibodies specific for galactose-alpha-1,3-galactose. Allergy. 2012;67:699-704

14. Hilger C, Fischer J, Swiontek K, Hentges F, Lehners C, Eberlein B, et al. Two galactose-alpha-1,3-galactose carrying peptidases from pork kidney mediate anaphylactogenic responses in delayed meat allergy. Allergy. 2016;71:711-9 First study on meat proteins isolated from pork kidney that were shown to induce basophil activation in patients with $\alpha$-Gal syndrome.

15. Apostolovic D, Tran TA, Hamsten C, Starkhammar M, Cirkovic Velickovic T, van Hage M. Immunoproteomics of processed beef proteins reveal novel galactose-alpha-1,3-galactose-containing allergens. Allergy. 2014;69:1308-15.

16. Takahashi H, Chinuki Y, Tanaka A, Morita E. Laminin gamma-1 and collagen alpha-1 (VI) chain are galactose-alpha-1,3-galactosebound allergens in beef. Allergy. 2014;69:199-207.

17. Commins SP, James HR, Kelly LA, Pochan SL, Workman LJ, Perzanowski MS, et al. The relevance of tick bites to the production of $\mathrm{IgE}$ antibodies to the mammalian oligosaccharide galactose-alpha-1,3-galactose. J Allergy Clin Immunol. 2011;127:12861293.e1286.

18. Van Nunen SA, O'Connor KS, Clarke LR, Boyle RX, Fernando SL. An association between tick bite reactions and red meat allergy in humans. Med J Aust. 2009;190:510-1.

19. Chinuki Y, Ishiwata K, Yamaji K, Takahashi H, Morita E. Haemaphysalis longicornis tick bites are a possible cause of red meat allergy in Japan. Allergy. 2016;71:421-5.

20. Hamsten C, Starkhammar M, Tran TA, Johansson M, Bengtsson U, Ahlen $\mathrm{G}$, et al. Identification of galactose-alpha-1,3-galactose in the gastrointestinal tract of the tick Ixodes ricinus; possible relationship with red meat allergy. Allergy. 2013;68:549-52.

21.• Araujo RN, Franco PF, Rodrigues H, Santos LC, McKay CS, Sanhueza CA, et al. Amblyomma sculptum tick saliva: alpha-Gal identification, antibody response and possible association with red meat allergy in Brazil. Int J Parasitol. 2016;46:213-20 This publication together with reference 83 , Ohta et al., points to a possible explanation for the Th2 triggering capacity of repeated tick bites and the consecutive production of $\alpha$-Gal specific IgE.

22. Stoltz LP, Cristiano LM, Dowling APG, Wilson JM, Platts-Mills TAE, Traister RS. Could chiggers be contributing to the prevalence of galactose-alpha-1,3-galactose sensitization and mammalian meat allergy? J Allergy Clin Immunol Pract. 2018. https://doi.org/10. 1016/j.jaip.2018.07.014.

23. van Nunen S. Tick-induced allergies: mammalian meat allergy, tick anaphylaxis and their significance. Asia Pac Allergy. 2015;5:3-16.

24. Fischer J, Lupberger E, Hebsaker J, Blumenstock G, Aichinger E, Yazdi AS, et al. Prevalence of type I sensitization to alpha-gal in forest service employees and hunters. Allergy. 2017;72:1540-7 Demonstrates that $8 \%$ of $\alpha$-Gal sensitized individuals $(>$ $0.35 \mathrm{kU}$ ) with high risk for experiencing tick bites are $\alpha-\mathrm{Gal}$ allergic and that the risk correlates with the number of tick bites.

25. Villalta D, Pantarotto L, Da Re M, Conte M, Sjolander S, Borres MP, et al. High prevalence of sIgE to galactose-alpha-1,3-galactose in rural pre-Alps area: a cross-sectional study. Clin Exp Allergy. 2016:46:377-80.

26. Gonzalez-Quintela A, Dam Laursen AS, Vidal C, Skaaby T, Gude F, Linneberg A. IgE antibodies to alpha-gal in the general adult population: relationship with tick bites, atopy, and cat ownership. Clin Exp Allergy. 2014;44:1061-8.

27. Commins SP, James HR, Stevens W, Pochan SL, Land MH, King $\mathrm{C}$, et al. Delayed clinical and ex vivo response to mammalian meat in patients with IgE to galactose-alpha-1,3-galactose. J Allergy Clin Immunol. 2014;134:108-15 Confirms that the time course of clinical symptoms after the ingestion of mammalian meat in subjects with IgE to $\alpha$-Gal correlates with in vivo basophil activation during a food challenge.

28. Mehlich J, Fischer J, Hilger C, Swiontek K, Morisset M, CodreanuMorel F, et al. The basophil activation test differentiates between patients with alpha-gal syndrome and asymptomatic alpha-gal sensitization. J Allergy Clin Immunol. 2018. https://doi.org/10.1016/j. jaci.2018.06.049 Proposes the basophil activation test for differentiation between patients with $\alpha$-Gal syndrome and those with asymptomatic $\alpha$-Gal sensitization.

29. Hamsten C, Tran TA, Starkhammar M, Brauner A, Commins SP, Platts-Mills TA, et al. Red meat allergy in Sweden: association with tick sensitization and B-negative blood groups. J Allergy Clin Immunol. 2013;132:1431-4.

30. Cabezas-Cruz A, de la Fuente J, Fischer J, Hebsaker J, Lupberger E, Blumenstock G, et al. Prevalence of type I sensitization to alpha-gal in forest service employees and hunters: is the blood type an overlooked risk factor in epidemiological studies of the alpha-Gal syndrome? Allergy. 2017;72:2044-7.

31. Galili U, Macher BA, Buehler J, Shohet SB. Human natural antialpha-galactosyl IgG. II. The specific recognition of alpha (13)-linked galactose residues. J Exp Med. 1985;162:573-82.

32. Galili U. Significance of the evolutionary alpha1,3galactosyltransferase (GGTA1) gene inactivation in preventing extinction of apes and old world monkeys. J Mol Evol. 2015;80:1-9.

33. Takeuchi Y, Porter CD, Strahan KM, Preece AF, Gustafsson K, Cosset FL, et al. Sensitization of cells and retroviruses to human serum by (alpha 1-3) galactosyltransferase. Nature. 1996;379:85-8.

34. Welsh RM, O'Donnell CL, Reed DJ, Rother RP. Evaluation of the Galalpha1-3Gal epitope as a host modification factor eliciting 
natural humoral immunity to enveloped viruses. J Virol. 1998;72: 4650-6.

35. Avila JL, Rojas M, Galili U. Immunogenic Gal alpha $1-3 \mathrm{Gal}$ carbohydrate epitopes are present on pathogenic American Trypanosoma and Leishmania. J Immunol. 1989;142:2828-34.

36. Ayoub D, Jabs W, Resemann A, Evers W, Evans C, Main L, et al. Correct primary structure assessment and extensive glyco-profiling of cetuximab by a combination of intact, middle-up, middle- down and bottom-up ESI and MALDI mass spectrometry techniques. MAbs. 2013;5:699-710.

37.• Yilmaz B, Portugal S, Tran TM, Gozzelino R, Ramos S, Gomes J, et al. Gut microbiota elicits a protective immune response against malaria transmission. Cell. 2014;159:1277-89 Mouse model showing that anti- $\alpha$-Gal antibodies are associated with protection against malaria transmission.

38. Posekany KJ, Pittman HK, Bradfield JF, Haisch CE, Verbanac KM. Induction of cytolytic anti-gal antibodies in alpha-1,3galactosyltransferase gene knockout mice by oral inoculation with Escherichia coli O86:B7 bacteria. Infect Immun. 2002;70:6215-22.

39. Cabezas-Cruz A, Mateos-Hernandez L, Alberdi P, Villar M, Riveau G, Hermann E, et al. Effect of blood type on anti-alpha-Gal immunity and the incidence of infectious diseases. Exp Mol Med. 2017;49:e301.

40. Soares MP, Yilmaz B. Microbiota control of malaria transmission. Trends Parasitol. 2016;32:120-30.

41. Iniguez E, Schocker NS, Subramaniam K, Portillo S, Montoya AL, Al-Salem WS, et al. An alpha-Gal-containing neoglycoproteinbased vaccine partially protects against murine cutaneous leishmaniasis caused by Leishmania major. PLoS Negl Trop Dis. 2017;11: e0006039.

42. Moura APV, Santos LCB, Brito CRN, Valencia E, Junqueira C, Filho AAP, et al. Virus-like particle display of the alpha-gal carbohydrate for vaccination against Leishmania infection. ACS Cent Sci. 2017;3:1026-31.

43. Galili U, Anaraki F, Thall A, Hill-Black C, Radic M. One percent of human circulating B lymphocytes are capable of producing the natural anti-Gal antibody. Blood. 1993;82:2485-93.

44. Galili U, Rachmilewitz EA, Peleg A, Flechner I. A unique natural human IgG antibody with anti- alpha-galactosyl specificity. J Exp Med. 1984;160:1519-31.

45. Galili U, Mandrell RE, Hamadeh RM, Shohet SB, Griffiss JM. Interaction between human natural anti-alpha-galactosyl immunoglobulin $\mathrm{G}$ and bacteria of the human flora. Infect Immun. 1988;56: 1730-7.

46. Galili U, Buehler J, Shohet SB, Macher BA. The human natural anti-Gal IgG. III. The subtlety of immune tolerance in man as demonstrated by crossreactivity between natural anti-Gal and anti-B antibodies. J Exp Med. 1987;165:693-704.

47. Lammerts van Bueren JJ, Rispens T, Verploegen S, van der PalenMerkus T, Stapel S, Workman LJ, et al. Anti-galactose-alpha-1,3galactose IgE from allergic patients does not bind alphagalactosylated glycans on intact therapeutic antibody Fc domains. Nat Biotechnol. 2011;29:574-6.

48. Chitnavis M, Stein DJ, Commins S, Schuyler AJ, Behm B. Firstdose anaphylaxis to infliximab: a case of mammalian meat allergy. J Allergy Clin Immunol Pract. 2017;5:1425-6.

49. Stone CA Jr, Commins SP, Choudhary S, Vethody C, Heavrin JL, Wingerter $\mathrm{J}$, et al. Anaphylaxis after vaccination in a pediatric patient: further implicating alpha-gal allergy. J Allergy Clin Immunol Pract. 2018.

50. Stone CA Jr, Hemler JA, Commins SP, Schuyler AJ, Phillips EJ, Peebles RS Jr, et al. Anaphylaxis after zoster vaccine: Implicating alpha-gal allergy as a possible mechanism. J Allergy Clin Immunol. 2017;139:1710-1713.e1712.
51. Vidal C, Mendez-Brea P, Lopez-Freire S, Gonzalez-Vidal T. Vaginal capsules: an unsuspected probable source of exposure to alpha-Gal. J Investig Allergol Clin Immunol. 2016;26:388-9.

52. Pinson ML, Waibel KH. Safe administration of a gelatin-containing vaccine in an adult with galactose-alpha-1,3-galactose allergy. Vaccine. 2015;33:1231-2.

53. Stone CA Jr, Hemler JA, Commins SP, Schuyler AJ, Phillips EJ, Peebles RS Jr, et al. Reply. J Allergy Clin Immunol. 2018;141: 1957-8.

54. Fischer J, Eberlein B, Hilger C, Eyer F, Eyerich S, Ollert M, et al. Alpha-gal is a possible target of IgE-mediated reactivity to antivenom. Allergy. 2017;72:764-71.

55. Rizer J, Brill K, Charlton N, King J. Acute hypersensitivity reaction to Crotalidae polyvalent immune Fab (CroFab) as initial presentation of galactose-alpha-1,3-galactose (alpha-gal) allergy. Clin Toxicol (Phila). 2017;55:668-9.

56. Swiontek K, Morisset M, Codreanu-Morel F, Fischer J, Mehlich J, Darsow U, et al. Drugs of porcine origin - a risk factor for patients with alpha-Gal syndrome? J Allergy Clin Immunol Pract. 2018. https://doi.org/10.1016/j.jaip.2018.12.005

57. Nunez-Orjales R, Martin-Lazaro J, Lopez-Freire S, Galan-Nieto A, Lombardero-Vega M, Carballada-Gonzalez F. Bovine amniotic fluid: a new and occupational source of galactose-alpha-1,3- galactose. J Investig Allergol Clin Immunol. 2017;27:313-4.

58. Naso F, Gandaglia A, Bottio T, Tarzia V, Nottle MB, d'Apice AJ, et al. First quantification of alpha-gal epitope in current glutaraldehyde-fixed heart valve bioprostheses. Xenotransplantation. 2013;20:252-61.

59. Hawkins RB, Frischtak HL, Kron IL, Ghanta RK. Premature bioprosthetic aortic valve degeneration associated with allergy to galactose-alpha-1,3-galactose. J Card Surg. 2016;31:446-8.

60. Wilson JM, Nguyen AT, Schuyler AJ, Commins SP, Taylor AM, Platts-Mills TAE, et al. IgE to the mammalian oligosaccharide galactose- $\alpha$-1,3-galactose is associated with increased atheroma volume and plaques with unstable characteristics - brief report. Arterioscler Thromb Vasc Biol. 2018;38:1665-9.

61. Galili U. In situ conversion of tumors into autologous tumorassociated antigen vaccines by intratumoral injection of alpha-gal glycolipids. Oncoimmunology. 2013;2:e22449.

62. Galili U, Wigglesworth K, Abdel-Motal UM. Intratumoral injection of alpha-gal glycolipids induces xenograft-like destruction and conversion of lesions into endogenous vaccines. J Immunol. 2007;178: 4676-87.

63. Macher BA, Galili U. The Galalpha1,3Galbeta1,4GlcNAc-R (alpha-Gal) epitope: a carbohydrate of unique evolution and clinical relevance. Biochim Biophys Acta. 1780;2008:75-88.

64. Thall AD, Maly P, Lowe JB. Oocyte Gal alpha 1,3Gal epitopes implicated in sperm adhesion to the zona pellucida glycoprotein $\mathrm{ZP} 3$ are not required for fertilization in the mouse. $\mathrm{J}$ Biol Chem. 1995;270:21437-40.

65. Tearle RG, Tange MJ, Zannettino ZL, Katerelos M, Shinkel TA, Van Denderen BJ, et al. The alpha-1,3-galactosyltransferase knockout mouse. Implications for xenotransplantation. Transplantation. 1996;61:13-9.

66. LaTemple DC, Galili U. Adult and neonatal anti-Gal response in knock-out mice for alpha1,3galactosyltransferase. Xenotransplantation. 1998;5:191-6.

67. Galili U, Korkesh A, Kahane I, Rachmilewitz EA. Demonstration of a natural antigalactosyl IgG antibody on thalassemic red blood cells. Blood. 1983;61:1258-64.

68. Galili U. Interaction of the natural anti-Gal antibody with alphagalactosyl epitopes: a major obstacle for xenotransplantation in humans. Immunol Today. 1993;14:480-2.

69. Cooper DK, Good AH, Koren E, Oriol R, Malcolm AJ, Ippolito $\mathrm{RM}$, et al. Identification of alpha-galactosyl and other carbohydrate epitopes that are bound by human anti-pig antibodies: relevance to 
discordant xenografting in man. Transpl Immunol. 1993;1:198205.

70. Sandrin MS, Vaughan HA, Dabkowski PL, McKenzie IF. Studies on human naturally occurring antibodies to pig xenografts. Transplant Proc. 1993;25:2917-8.

71. Sandrin MS, Vaughan HA, Dabkowski PL, McKenzie IF. Anti-pig IgM antibodies in human serum react predominantly with Gal (alpha 1-3) Gal epitopes. Proc Natl Acad Sci U S A. 1993;90: 11391-5.

72. Sorensen DB, Dahl K, Ersboll AK, Kirkeby S, d'Apice AJ, Hansen AK. Aggression in cataract-bearing alpha-1,3-galactosyltransferase knockout mice. Lab Anim. 2008;42:34-44.

73. Dahl K, Buschard K, Gram DX, d'Apice AJ, Hansen AK. Glucose intolerance in a xenotransplantation model: studies in alpha-gal knockout mice. Apmis. 2006;114:805-11.

74. Pearse MJ, Witort E, Mottram P, Han W, Murray-Segal L, Romanella M, et al. Anti-Gal antibody-mediated allograft rejection in alpha1,3-galactosyltransferase gene knockout mice: a model of delayed xenograft rejection. Transplantation. 1998;66:748-54.

75. Chiang TR, Fanget L, Gregory R, Tang Y, Ardiet DL, Gao L, et al. Anti-Gal antibodies in humans and 1,3alpha-galactosyltransferase knock-out mice. Transplantation. 2000;69:2593-600.

76. Cretin N, Bracy J, Hanson K, Iacomini J. The role of T cell help in the production of antibodies specific for Gal alpha 1-3Gal. J Immunol. 2002;168:1479-83.

77. McKenzie IF, Xing PX, Vaughan HA, Prenzoska J, Dabkowski PL, Sandrin MS. Distribution of the major xenoantigen (gal (alpha 13)gal) for pig to human xenografts. Transpl Immunol. 1994;2:81-6.

78. Tanemura M, Galili U. Differential expression of alpha-gal epitopes on pig and mouse organs. Transplant Proc. 2000;32:843.

79. Caponetto P, Biedermann T, Yazdi AS, Fischer J. Panitumumab: a safe option for oncologic patients sensitized to galactose-alpha-1,3galactose. J Allergy Clin Immunol Pract. 2015;3:982-3.

80. Roenneberg S, Bohner A, Brockow K, Arnold A, Darsow U, Eberlein B, et al. Alpha-gal-a new clue for anaphylaxis in mastocytosis. J Allergy Clin Immunol Pract. 2016;4:531-2.

81. Zhao Y, Rodriguez-Barbosa JI, Swenson K, Barth RN, Shimizu A, Arn JS, et al. The induction of 663 specific pig skin graft tolerance by grafting with neonatal pig thymus in thymectomized mice. Transplantation. 2000;69:1447-51.

82. Itoh M, Takahashi T, Sakaguchi N, Kuniyasu Y, Shimizu J, Otsuka F, et al. Thymus and autoimmunity: production of CD25+CD4+ naturally anergic and suppressive T cells as a key function of the thymus in maintaining immunologic self-tolerance. J Immunol. 1999; 162:5317-26.

83. Galili U. Anti-gal: an abundant human natural antibody of multiple pathogeneses and clinical benefits. Immunology. 2013;140:1-11.

84.• Ohta T, Yoshikawa S, Tabakawa Y, Yamaji K, Ishiwata K, Shitara $\mathrm{H}$, et al. Skin CD4(+) Memory T cells play an essential role in acquired anti-tick immunity through interleukin-3-mediated basophil recruitment to tick-feeding sites. Front Immunol. 2017;8:1348
Together with reference 21 , Araujo et al., this study points to a possible explanation for the Th2 triggering capacity of repeated tick bites and the consecutive production of $\alpha$-Gal specific IgE.

85. Min B, Prout M, Hu-Li J, Zhu J, Jankovic D, Morgan ES, et al. Basophils produce IL-4 and accumulate in tissues after infection with a Th2-inducing parasite. J Exp Med. 2004;200:507-17.

86. van Panhuys N, Prout M, Forbes E, Min B, Paul WE, Le Gros G. Basophils are the major producers of IL- 4 during primary helminth infection. J Immunol. 2011;186:2719-28.

87. Altmann F. The role of protein glycosylation in allergy. Int Arch Allergy Immunol. 2007;142:99-115.

88. Aalberse RC, Koshte V, Clemens JG. Immunoglobulin E antibodies that crossreact with vegetable foods, pollen, and Hymenoptera venom. J Allergy Clin Immunol. 1981;68:356-64.

89. Tretter V, Altmann F, Kubelka V, Marz L, Becker WM. Fucose alpha 1,3-linked to the core region of glycoprotein N-glycans creates an important epitope for $\mathrm{IgE}$ from honeybee venom allergic individuals. Int Arch Allergy Immunol. 1993;102:259-66.

90. Homann A, Schramm G, Jappe U. Glycans and glycan-specific IgE in clinical and molecular allergology: sensitization, diagnostics, and clinical symptoms. J Allergy Clin Immunol. 2017;140:356-68.

91. Moreno FJ, Montilla A, Villamiel M, Corzo N, Olano A. Analysis, structural characterization, 690 and bioactivity of oligosaccharides derived from lactose. Electrophoresis. 2014;35:1519-34.

92. Ohta M, Matsuura F, Kobayashi Y, Shigeta S, Ono K, Oka S. Further characterization of allergenically active oligosaccharitols isolated from a sea squirt $\mathrm{H}$-antigen. Arch Biochem Biophys. 1991;290:474-83.

93. Ohta M, Shigeta S, Ono K, Takao T, Shimonishi Y, Oka S. Sugar sequences of allergenically active oligosaccharide alcohols isolated from a large-molecular-size sea squirt antigen termed $\mathrm{H}$ - antigen. Arch Biochem Biophys. 1989;275:151-65.

94. Jyo T, Kuwabara M, Kodommari Y, Tanemori N, Asaoku Y, Katsutani T, et al. Cases of immediate-type allergy in oyster shuckers due to galacto-oligosaccharide. J Hiroshima Med Assoc. 1993;25:19-26.

95. Vo TH, Le NH, Patel MS, Phan LT, Tran Minh NN. Acute allergic reactions in Vietnamese children after drinking a new milk product. Foodborne Pathog Dis. 2012;9:156-9.

96. Chiang WC, Huang CH, Llanora GV, Gerez I, Goh SH, Shek LP, et al. Anaphylaxis to cow's milk 703 formula containing shortchain galacto-oligosaccharide. J Allergy Clin Immunol. 2012;130: 1361-7.

97. Trcka J, Schad SG, Scheurer S, Conti A, Vieths S, Gross G, et al. Rice-induced anaphylaxis: IgE- 705 mediated allergy against a 56kDa glycoprotein. Int Arch Allergy Immunol. 2012;158:9-17.

98.• Soh JY, Huang CH, Lee BW. Carbohydrates as food allergens. Asia Pac Allergy. 2015;5:17-24 Comprehensive review on carbohydrate-induced food allergy, highlights the unique characteristics of allergic reactions to $\alpha-\mathrm{Gal}$ and galactooligosaccharides (GOS). 